\title{
Balancing LV Distribution Networks in the Context of the Smart Gird
}

\author{
V. Fernão Pires*‡, Natália M.R. Santos*, Armando Cordeiro**, José L. Sousa *** \\ * INESC-ID Lisboa, SustainRD, Setúbal School of Technology, Polytechnic Institute of Setúbal, \\ 2910-761 Setúbal, Portugal \\ ** ADEEEA-Electrical Engineering Department, Energy and Automation, ISEL, \\ Instituto Politécnico de Lisboa, LCEC, 1959-007 Lisboa, Portugal \\ *** INESC Coimbra, SustainRD, Setúbal School of Technology, Polytechnic Institute of Setúbal, \\ 2910-761 Setúbal, Portugal \\ (vitor.pires@estsetubal.ips.pt, natalia.santos@estsetubal.ips.pt, acordeiro@deea.isel.ipl.pt, jose.luis.sousa@estsetubal.ips.pt) \\ $¥$ V. Fernão Pires; ESTSetúbal Campus do IPS, Setúbal, Portugal, \\ Tel: +351 265790000, vitor.pires@estsetubal.ips.pt \\ Received: $x x . x x . x x x x$ Accepted:xx.xx.xxxx
}

\begin{abstract}
One of the problems that Low Voltage (LV) distribution networks face is related to unbalance loads. These networks are characterized by the existence of single-phase loads that will unbalance the network. Due to this, there are higher losses, voltage unbalances and the possibility to emerge voltage levels that are not accepted by the legislation. However, the change in the actual paradigm regarding the integration of renewable energy sources (RES) in the LV distribution networks and the implementation of Smart-Grids (SG), will lead to the improvement of the quality of those networks. This work presents an overview of the technologies and strategies that have been introduced in the context of the Smart-Grids to attenuate the unbalance loads' related problems. To verify such impact, it will also be presented a study of a real network. This study will show the benefits resulting from the mitigation of this problem on the context of the SG.
\end{abstract}

Keywords Low-Voltage distribution network, Unbalance, Renewable Energy Sources, Smart-Grids, Ancillary services.

\section{Introduction}

The population growth and the consequent increase in demand for electricity, and climate change, led to an increasing urgency in new energy policies that foster the use of energy from renewable sources aiming the consequent reduction of $\mathrm{CO} 2$ emissions. In this context, electrical power networks are facing important challenges, including power generation from alternative renewable energy sources (RES), resulting in the development of distributed generation (DG). Among RES, solar energy is one of the main sources that have been receiving more attention. Incentive policies adopted by several countries, as well as increasing community awareness of environmental problems, have led to an increase in the demand for small photovoltaic (PV) units in the field of so-called micro generation [1-3]. As a consequence, the efficiency of PV systems have been increasing and the costs decreasing in recent years.

The penetration of DG systems has an impact in the low voltage (LV) network, being necessary the adoption of measures to optimize the system in order to improve the management of resources and the minimization of power losses, ensuring the legislation requirements. The DG systems in the network can change its behaviour, introducing some phenomena that may affect the operation of the electrical system, namely the bidirectional power flow between the transmission and the LV distribution networks. Voltage quality and stability problems may also arise from the deployment of DG systems in LV distribution networks [4-6]. LV distribution networks with high PV penetration usually present several problems. PV systems are designed to generate the maximum power for the grid. Since the PV power output is variable, PV systems connected to the grid create a problem to the its stability and reliability [2]. The ancillary systems (AS) are systems that provide the services required to enable the reliable operation of interconnected electric grid systems. The fulfilment of some requirements regarding voltage profiles, power balancing, quality of power, power factor compensation and power losses in the system are important for a reliable operation of the grid [7,8]. Another problem with PV systems is related to the nonsimultaneity between the periods of higher generation of energy and the ones of higher consumption. To solve this situation, the solution can be changing the consumption profile in order to adjust the demands of the network and/or the profile of production. However, in the actual context the change of the consumption profile it is only feasible to some 
extent, since it involves important changes in their lifestyle (working time periods, for instance) and consumption practices $[9,10]$.

In power systems it is necessary a permanent balance between supply and demand. It is then widely expected that energy storage resources will be required to overcome the afore mentioned non-simultaneity between solar generation and power demand, in order to enable renewables to provide reliable power. Then a solution to improve the reliability and the performance of these systems may go through the deployment of energy storage devices into the power system network [11-13]. This solution plays an important role in the integration of DG from renewable sources in the network, ensuring the satisfaction of consumption outside peak periods of production. However, one of the problems which have also been arising by the high integration of the renewable energy sources in $\mathrm{LV}$ networks is related to current unbalances. In fact, besides the unbalance originated by the load, these energy sources also contribute for current unbalance. Then, important increases of the unbalance can appear in those networks. In this context, this work will present an overview of several techniques used to attenuate or eliminate this problem. Recently there have been developments, specially related to renewable sources, storage systems and the role of Smart-Grids (SG). In fact, instead of contributing to the increase of the unbalance, those systems can be developed and controlled in order to attenuate or eliminate that problem. To verify such important impact, it will also be presented a case study in which a real LV network was used.

\section{Unbalance in LV Networks}

Distribution system operators usually consider that LV networks are a fully balanced system. However, this is not the case since it is extremely difficult to ensure an evenly distribution of single-phase loads through the phases. Moreover, the loads change over time, the allocation of new single-phase consumers is frequently not optimal, from the load balancing point of view, as well the structure of the loads in the network constantly changes. On the other hand, classical LV distribution networks are not designed for high penetration of RES, nor for storage systems. In fact, several studies have shown that the integration of these systems increase the problem with current unbalance in these networks [6, 14]. This unbalance can originate several problems on the grid, such as, the increase of line losses, voltage unbalance and overvoltage.

In the global context of LV networks, the best way to study and balance the network is through the analysis of the entire network. For the compensation of the unbalance, the integration in a SG allows to realize the best strategy [14, 15]. However, in order to study the best strategy for the balance of the network, it should also be implemented a power flow in order to analyse the complete network and verify the impact of the unbalance compensation in the entire network. Classical power flow methods cannot be used in these networks, since they were developed for three-phase networks with neutral line. Thus, several methods for studying load unbalances in networks with a neutral line were proposed. In this context, the two main techniques used were as follows:

- Deterministic power flow techniques;

- Probabilistic (uncertainty-based) power flow techniques.

Associated with the first technique several approaches have been proposed. However, most of them can be divided in the following methods:

- Backward/Forward Sweep (BFS) [6, 16];

- Newton Raphson (NR) [17,18];

- Gauss Z-Bus [19];

- Current Injection [20].

The techniques based on the probabilistic power flow techniques are based on the assumption that in LV networks many variables have a stochastic nature. This includes load demand and the renewable DG. The application of probabilistic power flow techniques was studied by several authors using the Monte Carlo simulation [21, 22]. Other approaches such as, multi-objective probabilistic power flow method and populistic power flow method, have also been used [21, 23].

One of the aspects that can be considered in the analysis and compensation of the LV networks is the existence of non-linear loads. However, the analysis of the LV networks taking into consideration such loads cannot be performed with the previous power flow methods. In such cases, the methods should be developed considering that the power flow is not only performed for the first harmonic, but also for the other harmonics. In this context, in [24] was presented a method that allowed the analysis and the compensation of overvoltages in LV networks with high PV penetration, considering the non-linear loads.

\section{Support for the Unbalanced LV Networks}

As described in the previous section the unbalance in $\mathrm{LV}$ networks originates several types of problems. In order to attenuate such unbalance several solutions have been proposed. One of the traditional solutions is load balancing through the reconfiguration of the connections of consumers $[25,26]$. However, the complete balance of the loads is very difficult to implement. On the other hand, the loads are not constant over time [27]. Thus, this solution practically never ensures the complete balance of the loads. Due to this, it is not possible to eliminate all the extra losses originated by the unbalance (it should be note that since the losses in the lines are function of the current square, even if the total load is the same the unbalance originate extra losses). On the other hand, it is also extremely difficult to ensure that the loads associated to each of the phase's presents the same reactive profile.

A more active solution can be provided with the introduction of extra equipment at the network level, as is the case of the unified power quality conditioner (UPQC) or 
distribution static compensator (dSTATCOM) [28, 29]. However, the connection of those equipment requires additional investments, as well as extra costs associated to their operation and maintenance. Besides that, the proposed studies also showed that this solution is normally implemented in a global context, i.e., normally it is only used one equipment that ensures a global compensation. Due to this, in several parts of the network there is not a full compensation of the balance. Thus, although be a better solution than the previous one, still originate extra losses.

Another proposed solution was the active allocation of the single-phase loads [30]. In this solution, those loads can change between phases using a Phase Switching Device (PSD). There are two possibilities for the implementation of this solution: installation of a PSD at each single-phase consumer with the possibility to connect to the three-phase grid, as shown in Fig. 1, or the installation of a PSD in some specific nodes of the grid in which the total load is considered as one load unit. Under the point of view of the compensation, this solution also presents several limitations. First, although a better balance can be achieved, it will be extremely difficult to ensure the full balance. Second, it will also be very difficult to ensure that the reactive character of the loads be exactly equal. In this way, with this solution there will be extra line losses due to the unbalance that still normally will exist. Another limitation is that, if the network has single and three-phase PV generators the unbalance will also be very difficult to achieve.

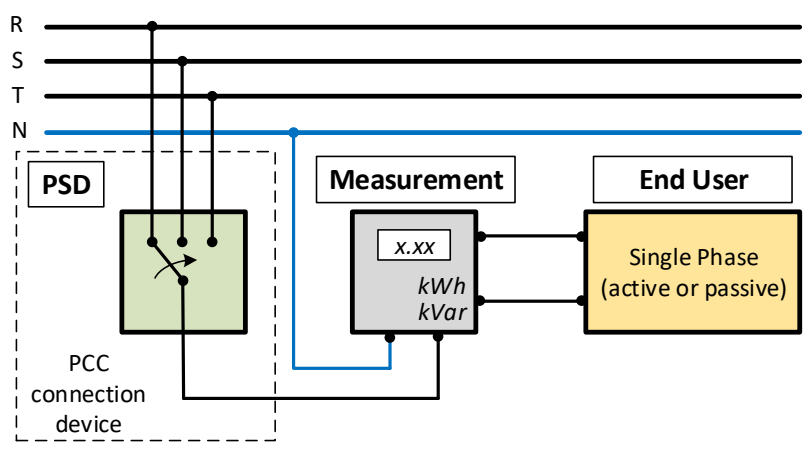

Fig. 1. Single-phase consumer with a PSD to switch the phase at which he is connected.

As described in the previous section, SG can play an important role in the actual context of the LV networks, namely regarding ancillary services. Among the several supports that can be provided by the DGs and storage systems, the compensation of the unbalance of currents and voltages in the LV networks could lead to a reduction of the line losses and improve the voltage profile [31]. As previously highlighted, these LV networks are characterized by the existence of single-phase loads that will unbalance the network. Due to the change of the LV paradigm in which appears the prosumer, that problem can also become worse since now there are also single-phase renewable generators and storage systems. However, those systems can be attached to a communication system (see Fig. 2) and be externally controlled in a way that they can provide ancillary services to attenuate the problem of the unbalance, instead of deteriorating it. In fact, SGs are fundamental in the optimization of the voltages of the LV network, through their monitoring and support giving as is the case of ancillary services [32].

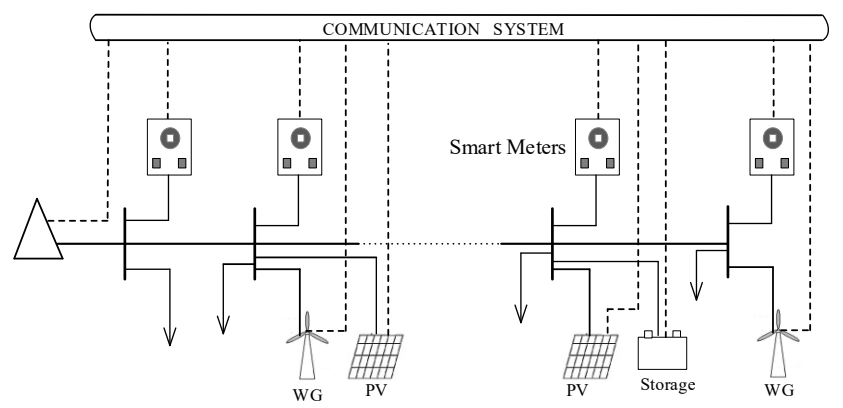

Fig. 2. Structure of renewable generators and storage systems connected to the grid.

One of the fundamental issues to compensate the unbalanced networks is the existence of a controlled renewable system and/or storage systems. Renewable systems like PVs require the use of power electronic converters to adapt the electrical characteristics of the PV panels to the characteristics of the LV grid (Fig. 3). Besides that, those converters are used to obtain the maximum power of the PV panels, or to limit power in order to avoid overvoltages.

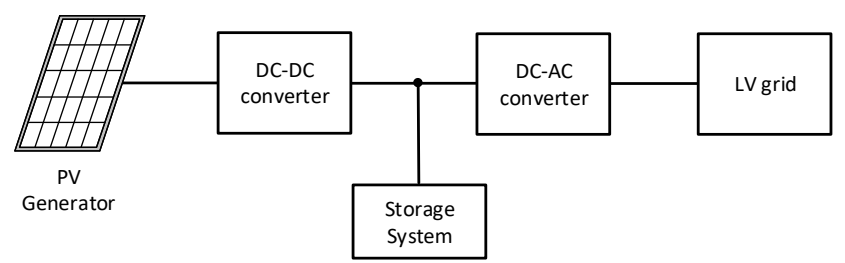

Fig. 3. Structure of a PV system connected to the grid.

Several studies have been made regarding the compensation of unbalanced LV networks with PV generators. This type of compensation can be done with single-phase or three-phase PV systems. In the context of single-phase PVs, the compensation will be ensured by controlling the power injected in the grid. In order to eliminate or reduce the unbalance, the connection of PV generators to the phases with lower load should be avoided or, at least, limited. However, this situation has the disadvantage of not fully use the potential available to generate renewable energy. This limitation can be overcome with three-phase PVs, where instead of a three-wire threephase inverter, a four-wire three-phase inverter should be used. Several studies have been made with the classical fourwire three-phase inverter [33]. Other topologies like the fourwire double-buck and quasi- $Z$ have also been studied to provide unbalance compensation [34-36].

Besides the decision on the power electronic topology to be used, it must also be considered the control that will be adopted. As a standard rule, the power converter is selected 
taking into consideration that its apparent power equals the maximum capacity of the PV source. In this situation, it is only possible to balance the active component of the load currents. Due to this, and since the loads are not purely resistive, it will not be possible to fully compensate the unbalance. However, the PV generator does not work at their maximum power all the time. Then it will be possible to also compensate the reactive component of the load [37, 38]. Another possibility is to oversize the inverter, although in this situation the cost of the system will increase. Other aspect that must be take into consideration regarding the unbalance compensation is the existence, or not, of nonlinear loads. The control must then be properly designed in order to specify what kind of unbalance should be considered. In fact, in this situation, besides the unbalance associated to the active and reactive components of the load currents, there are also unbalanced harmonic currents that must be taken into consideration. Then, there are the following three possibilities for the unbalance compensations:

- Compensation of the unbalance associated only to the reactive loads;

- Compensation of the unbalance associated only to the distorted currents;

- Compensation of all the unbalance (associated to both the reactive loads and distorted currents).

As previously mentioned, in all types of compensations it should also be stated that the compensation should be limited to the maximum apparent power capacity of the inverter. In Fig. 4 is presented a scheme of a possible controller for this system [36]. For the unbalance compensation it must be considered two possible conditions: power injected by the PV system lower than the load power and power injected by the PV system higher than the load power. Regarding the first condition all the currents injected from the PV system into the grid should be proportional to the load currents. The generation of the current references for the controller will be realized in the $d q o$ coordinates. Thus, for the second condition (power injected by the PV system is higher than the load power) the qo components of the current reference should be equal to the qo components of the load currents. The synchronous $d$ component of the current reference remains proportional to the $d$ component of the load. Another aspect of this system is if the non-linear loads are compensated or not. So, in the case of a grid with nonlinear loads, the currents are described by:

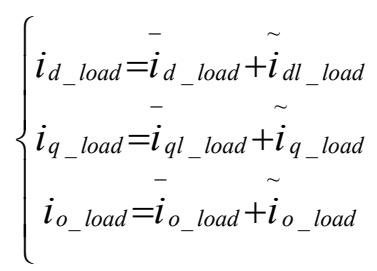

To compensate the linear and non-linear loads, the controller must consider the oscillatory current components. Otherwise, those components should be removed from the current references of the current controller. In Fig. 4a) the controller considers the compensation unbalance associated to both the linear and the non-linear loads (with harmonic compensation), while in the second scheme (Fig. 4 b)) it is only considered the compensation of linear loads (no harmonic compensation). Due to the limitation of the apparent power of the inverter, compensating only the unbalance of the first harmonic has the advantage of giving priority to this part. Anyway, the first scheme (Fig. 4 a)) allows to compensate the unbalance of both the linear and the non-linear loads and even the reactive power if iqref is considered different from zero.

The current controller can be implemented in the $\alpha \beta o$ coordinate system. To inject the PV generated active power into the grid in an unbalanced way, the three

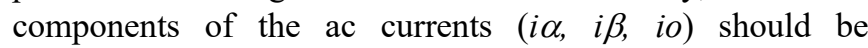
controlled. In this way, the following current control laws are obtained:

$$
\left\{\begin{array}{l}
S_{\alpha}=i_{\alpha_{-} r e f}-i_{\alpha} \\
S_{\beta}=i_{\beta_{-} r e f}-i_{\beta} \\
S_{o}=i_{o_{-} r e f}-i_{o}
\end{array}\right.
$$

At the output of the control laws, it can be used a vectorial modulator as the one defined in [39].

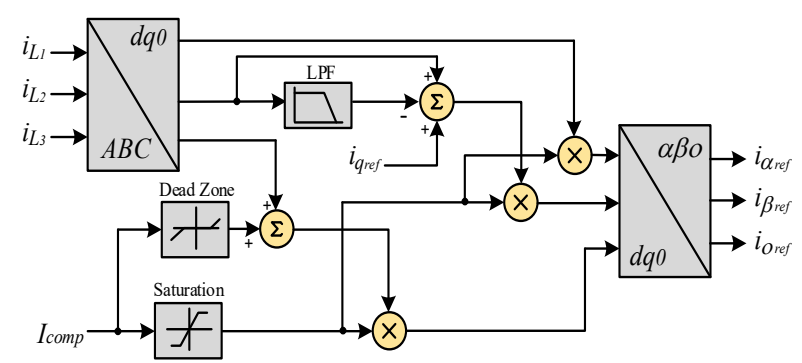

a) With harmonic compensation

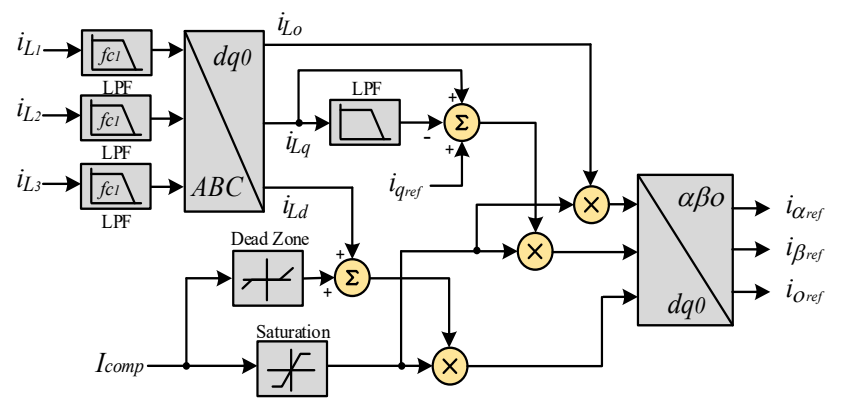

b) Without harmonic compensation.

Fig. 4. Control schemes for the inverter of the PV systems.

To balance the LV networks, several types of approaches were proposed, taking into consideration the equipment that are allocated to the grid. In fact, several works presented solutions to balance LV networks taking into consideration PV systems, electric vehicles (EV) chargers and storage systems. 
One of the approaches that have been proposed in the context of a SG was presented in the work [40]. Besides the proposal of using three-phase inverters with four-wire instead of the classical three-wire, it was also proposed a control strategy that considers the entire LV network. In this context it was proposed an algorithm to compensate unbalance of the active power that flows in the grid. The algorithm requires both consumer local measurement and the application of a power flow algorithm. Besides the algorithm for the active power it was also proposed another unbalance compensation algorithm but, in this case, for the reactive power. In this case, it will be possible to balance the currents demanded by consumers and at the same time compensate the reactive power also demanded using the remaining capacity of the converters. Comparing with the other solutions, when the generated PV power is equal or higher than the load, it can be considered as the best option. In fact, in this situation the load unbalance can many times be practically ensured, by which the extra losses will be practically eliminated. The disadvantage of this solution is that, when the generated PV power is lower (or even zero) than the load power then the unbalance cannot be ensured. However, although not yet implemented, this solution can be used together with one of the previous ones.

Another similar approach to balance the networks is through the use of electrical vehicles chargers [41]. In this case the balance is accomplished from the point of view of the flexible load. In fact, this is applied through the control of the three-phase rectifier. Here, the charger must receive less power from the phase that is overloaded and more power from the other phases. To achieve the desired goal, different controls were proposed and tested, such as i) controls for the active and the reactive power (active and reactive power drop control), ii) for the single-phase EV chargers and load balancing, and iii) for sequence compensation for the threephase EV chargers. However, this solution has also some drawbacks. Usually the fast chargers are connected to a line that is independent of the loads. Thus, although in some circumstances (load chargers equal or higher that the other loads) the full balance can be achieved, this is only ensured at the low voltage side of the transformer. In this way, even when a full balance is achieved, in several parts of the network the balance is not achieved, resulting in extra losses.

Another active approach is through the use of storage systems. In this situation the storage systems must be seen as both a load and a generator (see. Fig. 5). In the classical implementation are used three-phase storage systems that do not allow to storage all the generated energy from the PV generator. In this situation, in one or two phases, a certain amount of energy will flow to the grid (Fig. 5 a)). In this example it is possible to verify that the PV generator injects a balanced current. Since the storage system receives a balanced energy, it must be sized to receive all the power from the phase with lower load. As a result, some power generated by the PV will be injected into the grid. When the storage system works in generator mode the problem is similar. Since the load is unbalanced and the storage system delivers a balanced power in the all the phases, part of the required energy that should be supplied by the storage system was, in fact, supplied by the grid (Fig. 5 b)).

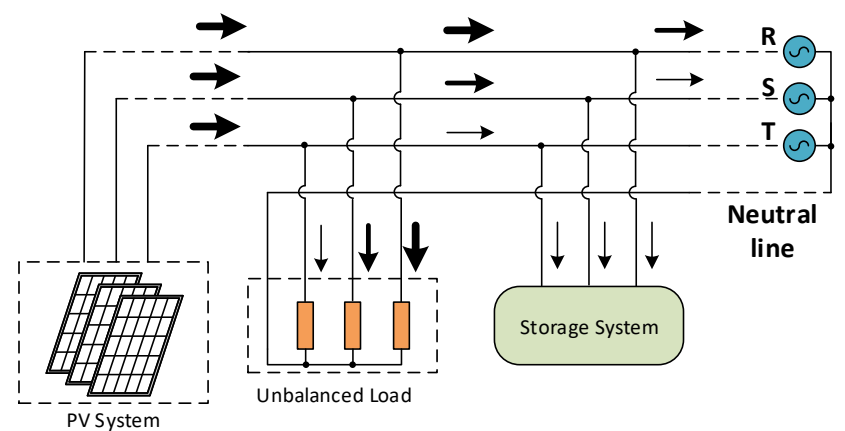

a) PV system injecting energy and storage system receiving energy.

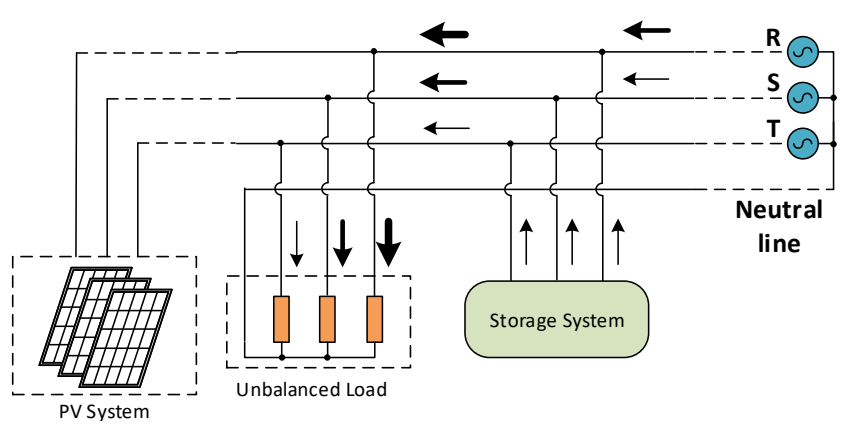

b) PV system disabled and storage system supplying the load.

Fig. 5. LV grid with unbalanced load, PV systems and storage systems using three-leg inverters.

To solve this problem, in [42] was proposed the use of a storage system that consists of a four-wire three-phase inverter, thus allowing the connection of both the phase lines and the neutral line. This way, if the storage system has the capability to receive all the energy in excess generated by the PV system and fully supply the load when needed, a fully compensation can be achieved (Fig. 6). This solution also presents some limitations. In fact, only when the storage systems are in operation or when the charge/discharge power is higher than the unbalanced load it is possible to ensure the balance. However, integrated with the solution with PV generators and/or electrical vehicles chargers can be one of the best solutions.

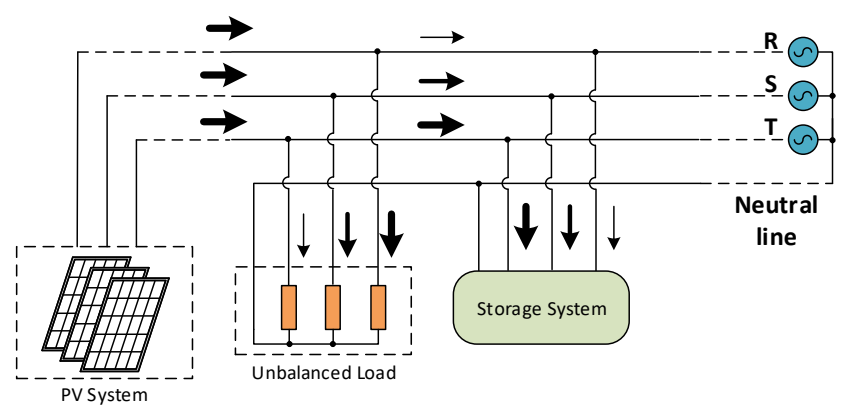

a) PV system injecting energy and storage system receiving energy. 


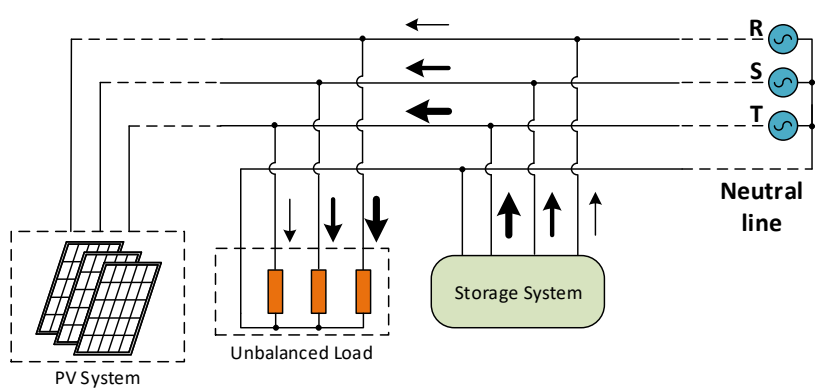

b) PV system disabled and storage system supplying the load.

Fig. 6. LV grid with unbalanced load, PV systems and storage systems using four-wire three phase inverters and balanced control.

\section{Case Study}

In this section, a case study is presented with the purpose of verifying the level of losses associated to the unbalance load in a typical LV grid. This study has also the purpose of analysing the level of losses reduction that can be achieved through the implementation of one of these solutions. It has also the purpose of verifying the impact in the voltage profile of the grid, namely if through the elimination/attenuation of the unbalance it is possible to ensure that the voltage profile will be in accordance with the standards. Among the several approaches, one of the most effective is the one associated to the control of the renewable sources. Thus, to show the effectiveness of this active control system, a LV test network with single and three-phase PV systems was used as a case study. The schematic of this network is depicted in Fig. 7. The case study network is composed by 12-bus LV radial feeder supplying 240 customers and it is connected to the medium-voltage (MV) network through a 15/04 kV transformer.

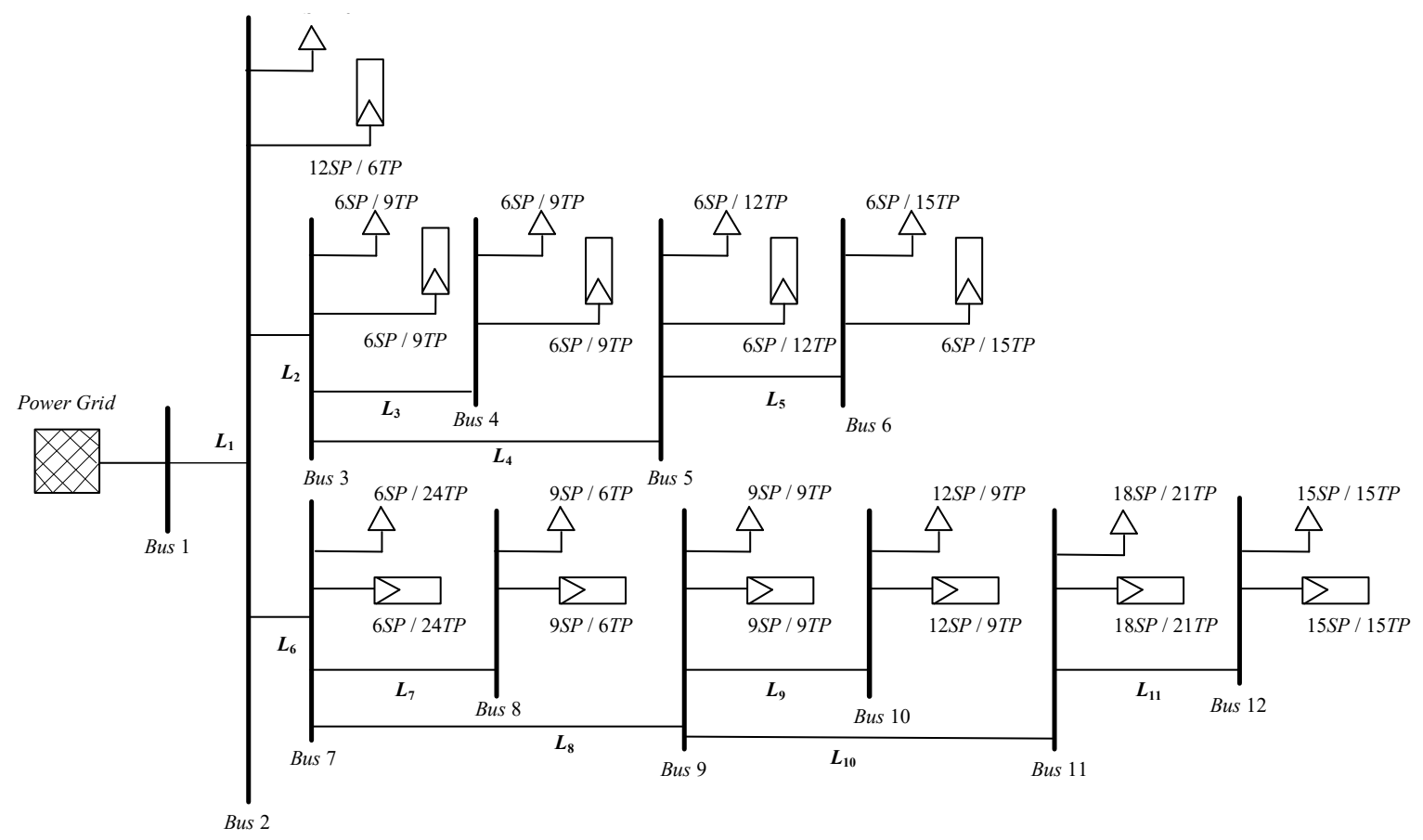

Fig. 7. Diagram of LV distribution network of the case study.

Several tests related to different situations and conditions were implemented in order to verify the impact of one of the most effective proposals, namely, the use of a control algorithm associated to the renewable sources [40]. Since the energy generated by the PV systems is not the same throughout the year, it was considered two extreme conditions, namely, the day with the highest irradiation (summer) and the day with the lowest irradiation (winter). With the purpose of verifying the impact of that strategy, it was considered the following four representative case studies:

- Without PV generation;

- With PV generation;
- With PV generation with active power unbalance compensation;

- With PV generation with active and reactive power unbalance compensation;

The power losses in each network line for each case study and for the day with higher irradiation are presented in Fig. 8. For the case study without PV generation, it can be observed (Fig. 8 (a)) that lines 2, 6, 9 and 10 are the ones with higher losses. This was expected, as they are the network lines associated with larger number of consumers. With the introduction of the PV generators the losses in the network lines present important increases (Fig. 8 (b)). These increases are due to the fact that the power generated by the 
PVs is much higher than the power consumed by the users. This situation also leads to a reverse power flow. However, for the active power unbalance compensation case study (PV generators injecting in an unbalanced way to compensate the unbalance) there was a reduction in those losses (Fig. 8 (c)). A further reduction of these losses is achieved when there is also an activation of the reactive power unbalance compensation (Fig. 8 (d)).

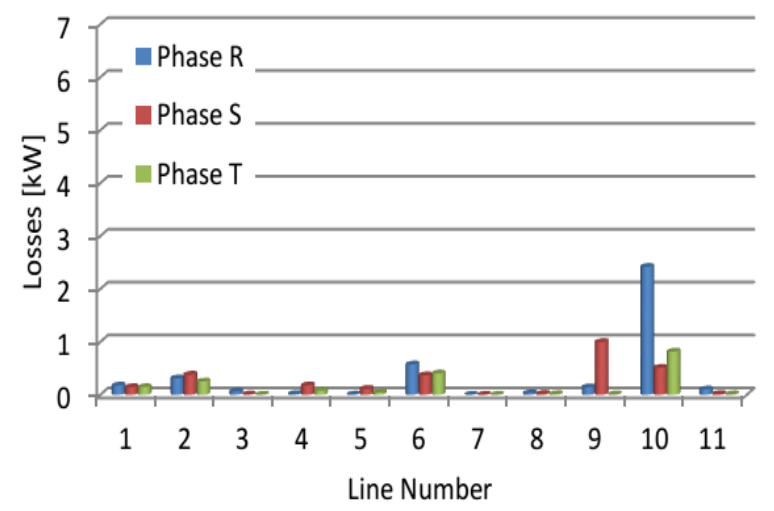

a) No PV production.

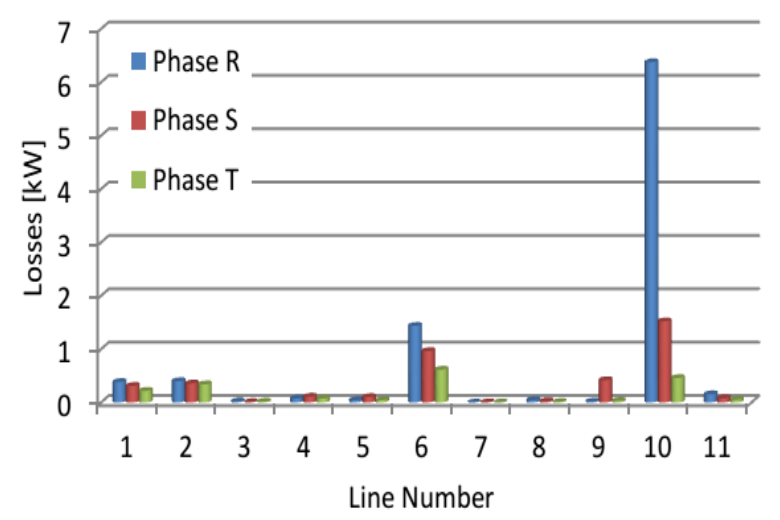

b) PV production with no active and reactive power unbalance compensation.

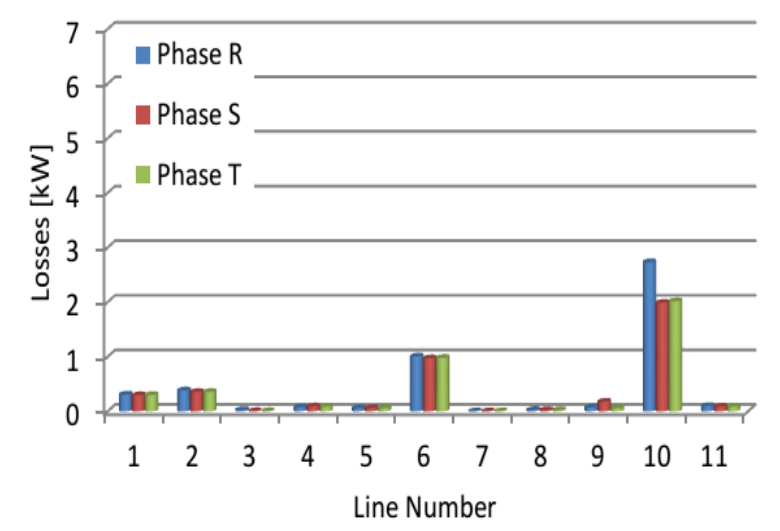

c) PV production with active power unbalance compensation and no reactive power unbalance compensation.

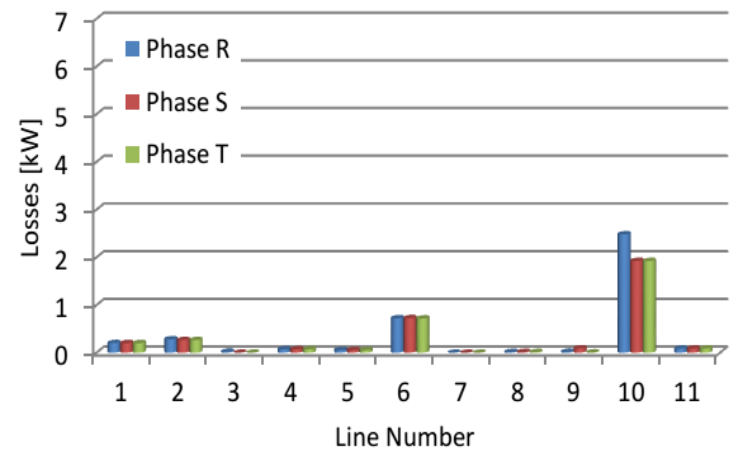

d) PV production with active and reactive power unbalance compensation.

Fig. 8. Line losses for the PV peak production and for the day with highest irradiation.

An analysis for the same case studies but considering the day with lowest irradiation was also performed. Fig. 9 presents the results obtained for the power losses in each line of the grid. Without PV generation the losses profile is very similar to the one of the days with higher irradiation, however, as presented in Fig. 9 (a) the losses in the day with lower irradiation are higher, because that day's consumption is also higher. With the introduction of the PV generators the losses decreased to very low values (Fig. 9 (b)). This is due to the fact that the power generated is similar to the power consumed by the users. It should be noted that in this day (peak of the winter) the consumed power is higher, and the generated power is lower. With the activation of the active power unbalance compensation, a situation similar to the illustrated in Fig. 9 (c) is obtained since there is a reduction of the line losses. With the reactive power unbalance compensation, a higher reduction in line losses is obtained, as shown in Fig. 9 (d).

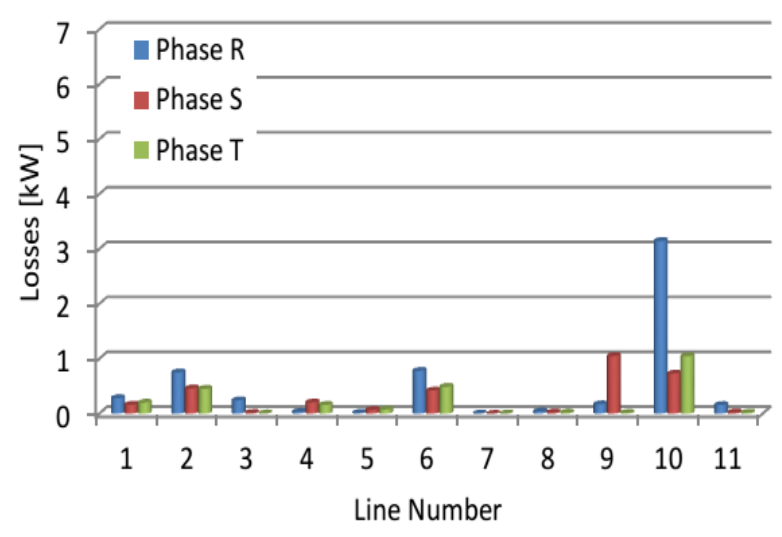

a) No PV production. 


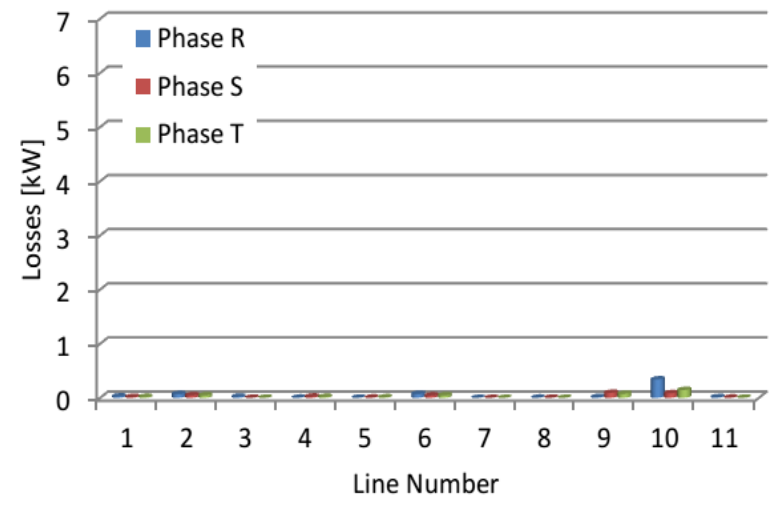

b) PV production with no active and reactive power unbalance compensation

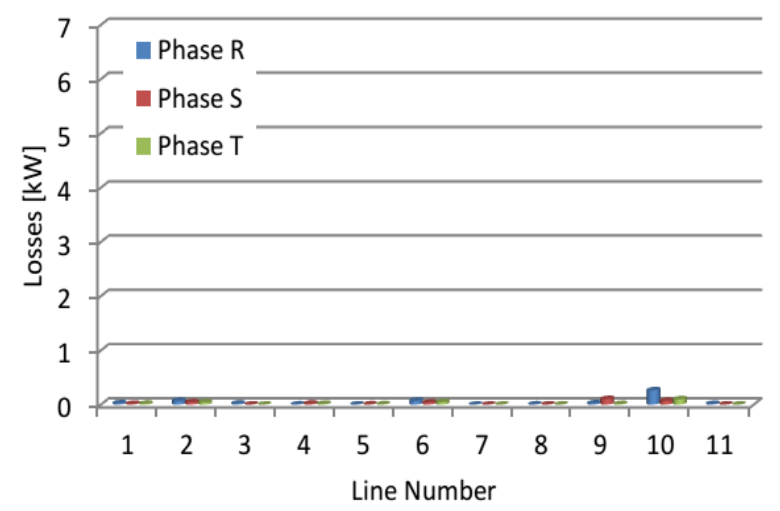

c) PV production with active power unbalance compensation and no reactive power unbalance compensation.

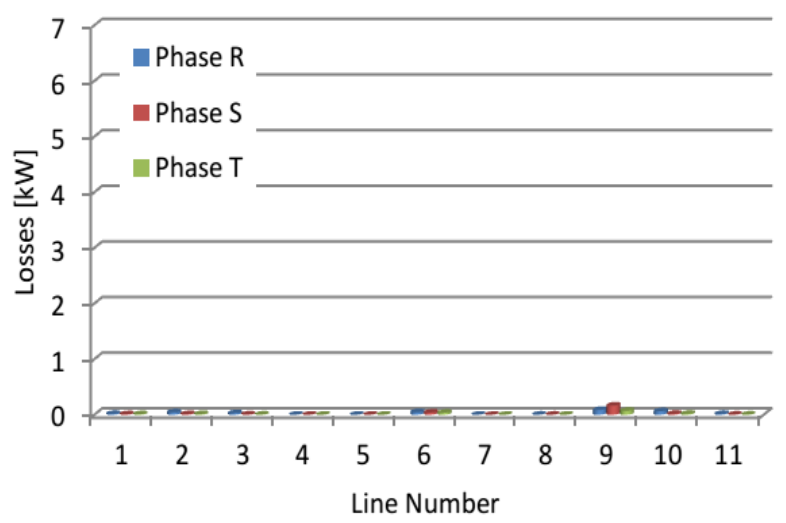

d) PV production with active and reactive power unbalance compensation.

Fig. 9. Line losses for the PV peak production and for the day with lowest irradiation.

The reduction of the losses in the lines has also impact on the voltage profile of the LV network. As expected, with the reduction of the losses such voltage profile will be improved. In Fig. 10 are presented the voltage profiles of each bus of the network, for the case studies referred above and for the day with higher irradiation level. In Fig. 10 (a) the voltage profile for the case study without PV generation is presented. It can be verified that the voltage values tend to decrease in the buses downstream. Through the voltage profiles of the different phases it is also possible to confirm the unbalance in the network, since the loads are unbalanced. With the introduction of PV generation there is much more energy produced than consumed, increasing the unbalance (Fig. 10 (b)). Also, instead of reducing the voltage values, these values generally increase at buses farthest from the transformer. Buses 11 and 12 are the ones that present the larger voltage unbalance, with an overvoltage in one of the phases that is $10 \%$ above of the nominal voltage, which does not respect the European standard. With PV generation and active power load unbalance compensation, it can be observed that there is a reduction of phases unbalance (Fig. 10 (c)), since the PV energy was injected in an unbalanced way to compensate the unbalanced loads. Besides the reduction of the unbalance there is also another very important aspect, namely the attenuation of the overvoltages. In fact, with this strategy it was possible to obtain, for all phases, overvoltages that are below $10 \%$, respecting the European standard. It is also important to highlight that it is not clear the advantage of using the reactive power unbalance compensation to improve the voltage profile (Fig. $10(d))$.

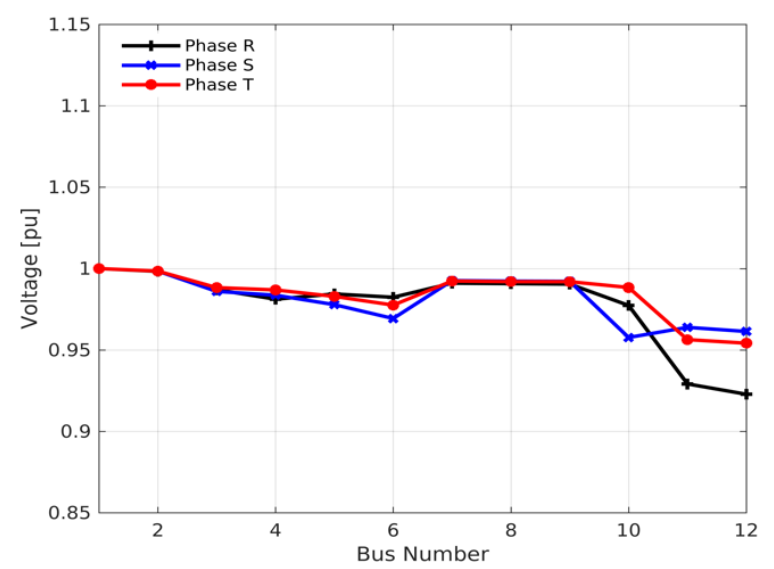

a) No PV production.

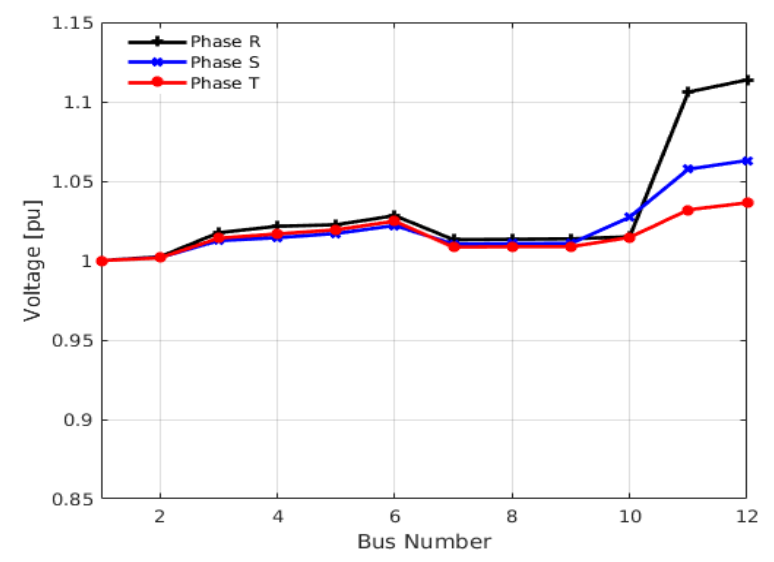

b) PV production with no active and reactive power unbalance compensation 


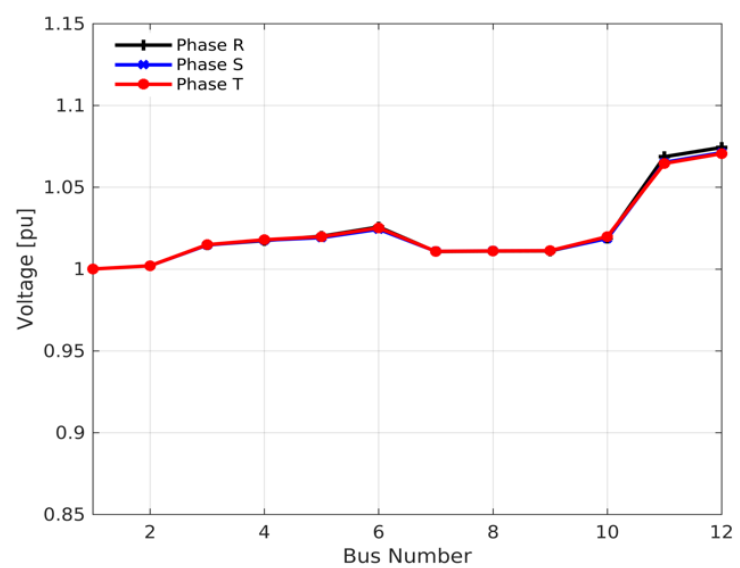

c) PV production with active power unbalance compensation and no reactive power unbalance compensation.

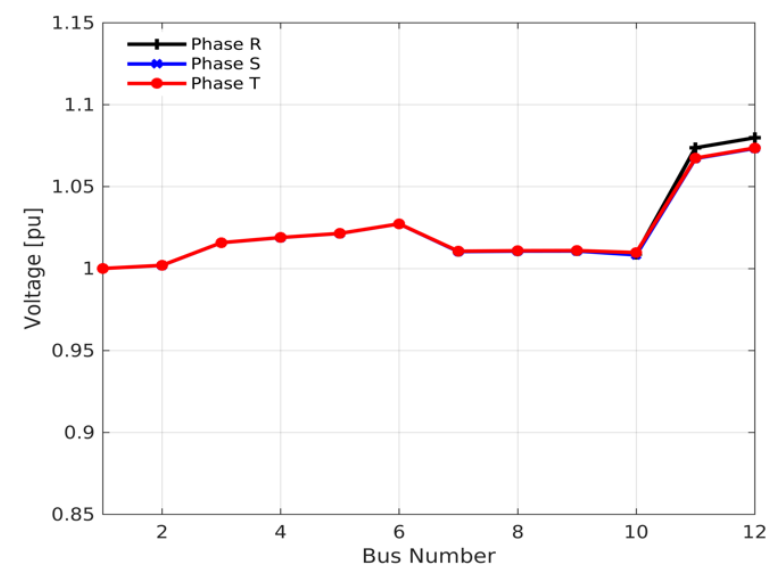

d) PV production with active and reactive power unbalance compensation.

Fig. 10. Voltage profile for the PV peak production and for the day with highest irradiation.

The voltage profiles for the day with lower irradiation levels and for the four representative case studies were also analyzed. Fig. 11 (a) presents the voltage profile of the network and it is possible to verify the similarity to the case of the day with higher irradiation level. Since this situation is for the network without PV generators, the voltage tends to decrease in the buses downstream. However, with the introduction of the PV generators, the bus voltages recover, being approximately 1 p.u. for all of them (Fig. 11 (b)). This is due to the fact that in this day the values of power generated by the PVs and of the energy consumption are very similar. This similarity is even higher when the active power load unbalance compensation is activated, as can be seen by Fig. 11 (c). Nevertheless, when the reactive power load unbalance compensation is activated, under the point of view of the voltage profile, there is a small deviation from the desired value of 1 p.u., especially for the farthest buses (Fig. $11(d))$.

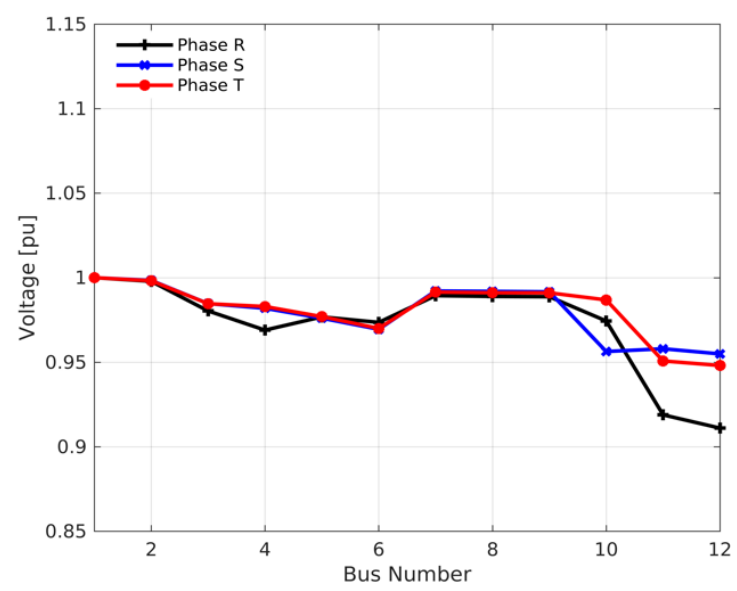

a) No PV production.

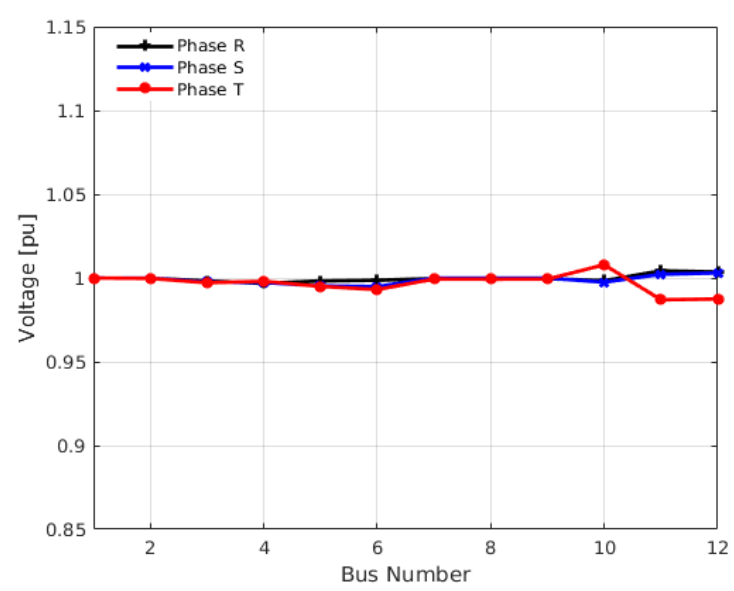

b) PV production with no active and reactive power unbalance compensation

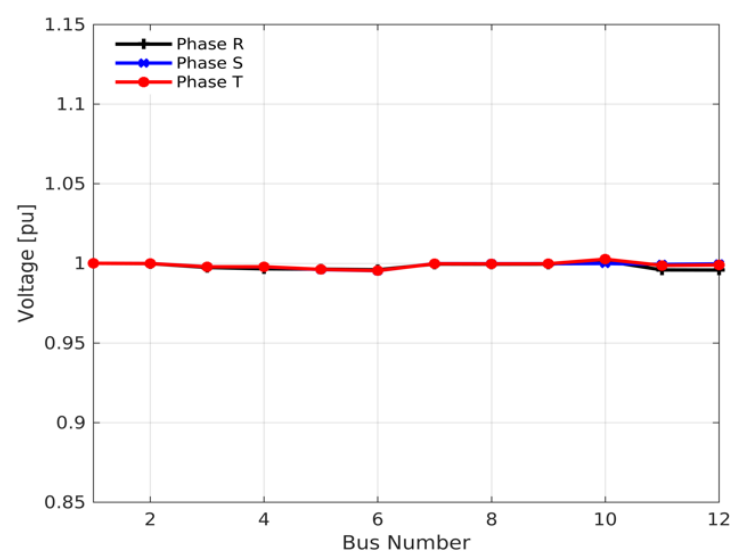

c) PV production with active power unbalance compensation and no reactive power unbalance compensation. 


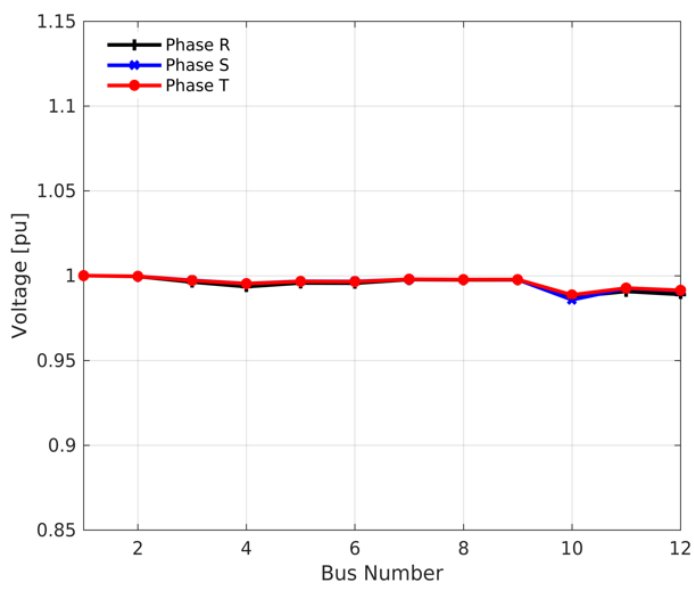

d) PV production with active and reactive power unbalance compensation.

Fig. 11. Voltage profile of the LV network for the PV peak production and for the day with lowest irradiation.
The total losses for the two days and for the four representative cases are also presented in table 1. From this table it is possible to verify that the line losses increase with the introduction of the PV systems and for the day with the highest irradiation. This is due to the excessive PV generation and the low consumption (day associated to the summer holidays). However, with the introduction of the unbalance compensation algorithm, besides the achievement of an injected balanced power into the connected point of the network, there is also a reduction of the line losses. This reduction is substantial since it reaches a value around $21 \%$. Regarding the day with the lowest irradiation, the introduction of the PV systems will allow the reduction of the line losses. This is due to the lowest generated PV energy and the higher consumption, since that day is associated to the peak of the winter. The use of the unbalance compensation algorithm also allows an even higher reduction of the line losses, achieving values of $41.5 \%$.

Table 1. Total losses for the two days and the four representative cases.

\begin{tabular}{|c|c|c|}
\cline { 2 - 3 } \multicolumn{1}{c|}{} & $\begin{array}{c}\text { Power Losses [kW] } \\
\text { Day with highest irradiation }\end{array}$ & $\begin{array}{c}\text { Power Losses [kW] } \\
\text { Day with lowest irradiation }\end{array}$ \\
\hline $\begin{array}{c}\text { Without PV production } \\
\text { Production with no active and reactive } \\
\text { power imbalance compensation }\end{array}$ & 8,438 & 11,325 \\
\hline $\begin{array}{c}\text { PV production with active power } \\
\text { imbalance compensation and no reactive } \\
\text { power imbalance compensation }\end{array}$ & 17,139 & 1,279 \\
\hline $\begin{array}{c}\text { PV production with active and reactive } \\
\text { power imbalance compensation }\end{array}$ & 15,122 & 0,067 \\
\hline
\end{tabular}

\section{Conclusions}

This work focused on the problem of the load unbalance that usually exists in LV networks. This problem can strongly affect these networks, namely, originating higher losses, voltages unbalances and voltage levels below the defined by legislation. Another problem that can be originated in grids with high PV penetration, is the possibility of reaching voltage levels above the defined by the legislation. Besides the description of several problems related with the load unbalance, this work presented an overview of the technologies and strategies to attenuate or eliminate this problem. It was verified that classical solutions are not the best way to achieve this objective. However, with the change of the paradigm that was verified in recent years, namely through the existence of the prosumers and the development of the SGs, new approaches have been proposed. This work also addressed this change of paradigm and the latest proposals for the attenuation or elimination of the unbalance problem in this context. The impact that the new approaches can have in the voltages of the LV network was also presented in this work. For this case study it was used four-wire three-phase inverters for the PV systems associated to an unbalance compensation algorithm for the active and reactive power. The results showed that it is possible to balance the loads, when the power generated by the PV systems is enough. The results also showed that there is also a reduction online loss of the LV network. That reduction will allow to substantially optimize the LV networks.

\section{Acknowledgements}

The work reported in this article was supported by national funds through FCT under contracts UID/CEC/50021/2019 and UID/MULTI/00308/2019.

\section{References}

[1] P. Sritakaew1, A. Sangswang, K. Kirtikara, "On the Reliability Improvement of Distribution Systems Using PV Grid-Connected Systems", ECTI Transactions on Electrical Eng., Electronics, and Communications Vol.5, No.1 February 2007.

[2] M. Yesilbudak, M. Colak, R. Bayindir, "What are the Current Status and Future Prospects in Solar Irradiance and Solar Power Forecasting?", International Journal of 
Renewable Energy Research, Vol. 8, No. 1, pp. 635-648, March 2018.

[3] S. Chowdhury, S. P. Chowdhury and P. Crossley, "Microgrids and Active Distribution Networks," IET Renewable Energy series 6, The Institution of Engineering and Technology, 2009.

[4] A. Manzoni, R. Castro, "Microgeneration Impact on LV Distribution Grids: A Review of Recent Research on Overvoltage Mitigation Techniques", International Journal of Renewable Energy Research, Vol. 6, No. 1, pp. 117-131, March 2016.

[5] L. F. Ochoa and G. P. Harrison, "Minimizing energy losses: Optimal accommodation and smart operation of renewable distributed generation", IEEE Transactions on Power Systems, Vol.26, No.1, pp.198-205, February 2011.

[6] F. Camilo, R. Castro, M. E. Almeida, V. F. Pires, "Selfconsumption and storage as a way to facilitate the integration of renewable energy in low voltage distribution networks", IET Generation Transm. Distrib., vol. 10, Issue 7, pp. 1741-1748, 2016.

[7] M. S. ElNozahy, M. M. A. Salama, "Technical impacts of grid-connected photovoltaic systems on electrical networks-A review", Journal of Renewable and Sustainable Energy, Vol.5, No.3, May 2013.

[8] P. Chaudhary, M. Rizwan, "Voltage regulation mitigation techniques in distribution system with high PV penetration: A review", Renewable and Sustainable Energy Reviews, Vol. 82, No. 3, pp. 3279-3287, February 2018.

[9] S. Sofana Reka, V. Ramesh, "A Novel Integrated Approach of Energy Consumption Scheduling in Smart Grid Environment with the Penetration of Renewable Energy", International Journal of Renewable Energy Research, Vol. 5, No. 4, pp. 1196-1205, December 2015.

[10] Z. Wang, C. Gu, F. Li, P. Bale and H. Sun, “Active Demand Response Using Shared Energy Storage for Household Energy Management", IEEE Transactions on Smart Grid, Vol. 4, No. 4, pp. 1888-1897, Dec. 2013.

[11] K.C. Divya, Jacob Østergaard, "Battery energy storage technology for power systems-An overview", Electric power systems research, Vol. 79, No. 4, pp. 511-520, April 2009.

[12] V. F. Pires, R. Lopes, D. Costa, "Integration of Storage Systems in Distribution Networks Through Multiobjective Optimization", Electrical Engineering, vol. 100, Issue 3, pp. 1939-1948, September 2018.

[13] N. Ghaffarzadeh, M. Zolfaghari, F. J. Ardakani, A. J. Ardakani, "Optimal Sizing of Energy Storage System in a Micro Grid Using the Mixed Integer Linear Programming", International Journal of Renewable Energy Research, Vol. 7, No. 4, pp. 2004-2016, December 2017.
[14] A. Rodriguez-Calvo, R. Cossent, P. Frías, "Integration of PV and EVs in unbalanced residential LV networks and implications for the smart grid and advanced metering infrastructure deployment", International Journal of Electrical Power \& Energy Systems, Vol. 91, pp. 121-134, October 2017.

[15] A. Baran, T. Fernandes, "A three-phase optimal power flow applied to the planning of unbalanced distribution networks", International Journal of Electrical Power \& Energy Systems, vol. 74, pp. 301-309, January 2016.

[16] S. Moghaddas-Tafreshi, E. Mashhour, "Distributed generation modeling for power flow studies and a threephase unbalanced power flow solution for radial distribution systems considering distributed generation", Electric Power Systems Research, vol. 79, N. 4, pp. 680-686, April 2009.

[17] B. Sereeter, K. Vuik, C. Witteveen, "Newton power flow methods for unbalanced three-phase distribution networks", Energies, vol. 10, Issue 10, pp. 1-20, October 2017.

[18] D. Fetzer, G. Lammert, S. Gehler, J. Hegemann, R. Schmoll, M. Braun, "Integration of voltage dependent power injections of distributed generators into the power flow by using a damped Newton method" International Journal of Electrical Power \& Energy Systems, Vol. 99, pp. 695-705, July 2018.

[19] J. Teng, "A modified Gauss-Seidel algorithm of threephase power flow analysis in distribution networks", International Journal of Electrical Power \& Energy Systems, vol. 24, Issue 2, pp. 97-102, February 2002.

[20] P. Garcia, J. Pereira, S. Carneiro, M. Vinagre, F. Gomes, "Improvements in the representation of PV buses on three-phase distribution power flow", IEEE Transactions on Power Delivery, vol. 19, Issue 2, pp. 894-896, April 2004.

[21] G. Gruosso, P. Maffezzoni, Z. Zhang, L. Daniel, "Probabilistic load flow methodology for distribution networks including loads uncertainty", International Journal of Electrical Power \& Energy Systems, vol. 106, pp. 392-400, March 2019.

[22] V. Klonari, B. Meersman, D. Bozalakov, T. Vandoorn, L. Vandevelde, J. Lobry, F. Vallée, "A probabilistic framework for evaluating voltage unbalance mitigation by photovoltaic inverters", Sustainable Energy, Grids and Networks, vol. 8, pp. 1-11, December 2016.

[23] G. Mokryani, A. Majumdar, B. Pal, "Probabilistic method for the operation of three-phase unbalanced active distribution networks", IET Renewable Power Generation, vol. 10, Issue 7, pp. 944-954, August 2016.

[24] F. M. Camilo, V. F. Pires, R. Castro, M. E. Almeida, "The Impact of Harmonics Compensation Ancillary Services of Photovoltaic Microgeneration in Low Voltage Distribution Networks", Sustainable Cities and Society, vol. 39, pp. 449-458, May 2018. 
[25] J. Zhu, M. Chow, F. Zhang, "Phase balancing using mixed-integer programming [distribution feeders]", IEEE Transactions on Power Systems, vol. 13, Issue 4, pp. 1487-1492, November 1998.

[26] A. Pasdar, H. Mehne, "Intelligent three-phase current balancing technique for single-phase load based on smart metering", International Journal of Electrical Power \& Energy Systems, vol. 33, Issue 3, pp. 693698, March 2011.

[27] M. Dilek, R. Broadwater, J. Thompson, R. Seqiun, "Simultaneous phase balancing at substations and switches with time-varying load patterns", IEEE Transactions on Power Systems, vol. 16, Issue 4, pp. 922-288, November 2001.

[28] D. Graovac, V. Katic, A. Rufer, "Power quality problems compensation with universal power quality conditioning system" IEEE Transactions on Power Delivery, vol. 22, Issue 2, pp. 968-976, April 2007.

[29] K. Li, J. Liu, Z. Wang, B. Wei, "Strategies and Operating Point Optimization of STATCOM Control for Voltage Unbalance Mitigation in Three-Phase Three-Wire Systems", IEEE Transactions on Power Delivery, vol. 22, Issue 1, pp. 413-422, January 2007.

[30] M. Usman, M. Coppo, F. Bignucolo, R. Turri, A. Cerretti, "A novel methodology for the management of distribution network based on neutral losses allocation factors", International Journal of Electrical Power \& Energy Systems, vol. 110, pp. 613-622, September 2019.

[31] J. L. Sousa, C. J. Brito, V. F. Pires, "Impact of Photovoltaic Systems with Ancillary Services in Low Voltage Grids", 15th Biennial Baltic Electronics Conference, Tallinn, pp 183-186, 3-5 October 2016.

[32] S. Massoud Amin, B. F. Wollenberg, "Toward a smart grid: power delivery for the 21st century," IEEE Power and Energy Magazine, vol. 3, no. 5, pp.34-41, September-October 2005.

[33] V. F. Pires, O. Husev, D. Vinnikov, J. F. Martins, “A Control Strategy for a Grid-Connected PV System with Unbalanced Loads Compensation", 9th International Conference on Compatibility and Power Electronics, Caparica, pp. 154-159, 24-26 June 2015.

[34] V. Fernão Pires, E. Romero-Cadaval, C. RonceroClemente, J. F. Martins, "A Grid-Connected PV System Based on a Four Wire Dual-Buck Inverter with Ancillary Services Support", 42nd Annual Conference of the IEEE Industrial Electronics Society, Florence, pp. 6534-6539, 24-27 Oct. 2016.
[35] O. Husev, E. Makovenko, D. Vinnikov, C. RonceroClemente, E. Romero-Cadaval, T. Jalakas, J. F. Martins, V. D. Gomes, V. F. Pires, "Single-Phase qZSbased PV Inverter with Storage Integration for Distributed Energy Generation", 12th International Conference on Compatibility, Power Electronics and Power Engineering, Doha, pp 1-6, 10-12 April 2018.

[36] V. Fernão Pires, Armando Cordeiro, Carlos RonceroClemente, J. F. Martins, "Control Strategy for a FourWire T-Type qZSI based PV System to Support Grids with Unbalanced Non-Linear Loads", 13th International Conference on Compatibility, Power Electronics and Power Engineering, Sønderborg, pp 1-6, 23-25 April 2019.

[37] H. Yu, J. Pan, A. Xiang, "A multi-function gridconnected PV system with reactive power compensation for the grid," Solar Energy, vol. 79, no. 1, pp. 101-106, 2005.

[38] V. F. Pires, J. F. Martins, J. Fernando Silva, “A Control Structure for a Photovoltaic Supply System with Power Compensation Characteristics Suitable for Smart Grid Topologies", 8th International Conference-Workshop Compatibility and Power Electronics, Ljubljana, pp 4045, 5-7 June 2013.

[39] V. F. Pires, D. Foito, A. Cordeiro, J. F. Martins, "Three-Phase T-Type qZ Source Inverter with Control Current Associated to a Vectorial Modulator for Photovoltaic Applications", 11th International Conference on Compatibility, Power Electronics and Power Engineering, pp 656-661, 4-6 April, 2017.

[40] F. Barrero-González, V. F. Pires, J. L. Sousa, J. F. Martins, M. I. Milanés-Montero, E. González-Romera, E. Romero-Cadaval, "Photovoltaic Power Converter Management in Unbalanced Low Voltage Networks with Ancillary Services Support", Energies, vol. 12, Issue 6, pp. 1-16, March 2019.

[41] J. Nájera, H. Mendonça, R. M. de Castro, J. R. Arribas, "Strategies Comparison for Voltage Unbalance Mitigation in LV Distribution Networks Using EV Chargers", Electronics, vol. 8, Issue 3, pp. 1-17, March 2019.

[42] V. F. Pires, J. F. Martins, C. Roncero-Clemente, E. Romero-Cadaval, O. Husev, "Controlling a Battery Energy Storage System to Support Residential Photovoltaic Installations", 26th International Symposium on Industrial Electronics, Edinburgh, pp 1769-1774, 19-21 June 2017. 